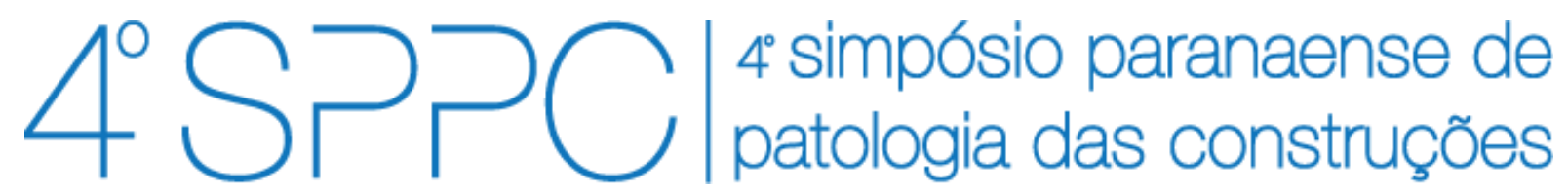

ISSN 2526-7248 artigo n. 4SPPC149, pp. 439-448, 2019

\title{
Influência de materiais pozolânicos na resistividade elétrica superficial do concreto
}

\author{
Real, Lígia V. ${ }^{1}$; Wosniack, Laís M. ${ }^{2}$; Silva, Melissa D. ${ }^{3}$; Medeiros, Marcelo H. F. 4 \\ ${ }^{1}$ Doutoranda, Engenheira Civil, EPUSP, ligiavr@usp.br \\ 2 Engenheira Civil, UTFPR, laismw@gmail.com \\ ${ }^{3}$ Engenheira Civil, UNIFACEAR, melissadione73@gmail.com \\ ${ }^{4}$ Professor Doutor, UFPR, medeiros.ufpr@gmail.com
}

\begin{abstract}
Resumo: A resistividade elétrica do concreto é um parâmetro importante para a avaliação da durabilidade do concreto armado, pois ela regula a velocidade de corrosão quando o aço se encontra em estado de corrosão ativa. Neste contexto, o objetivo deste estudo é investigar a influência das adições pozolânicas na resistividade elétrica do concreto medida pelo método dos 4 eletrodos. Para isso, foram moldados corpos de prova de cimento CPV ARI com diferentes adições pozolânicas, sendo elas: sílica ativa, cinza da casca do arroz, metacaulim e cinza volante. Estas adições foram usadas em substituição parcial do cimento Portland com teor de $10 \%$. Os resultados mostraram que as adições pozolânicas impactaram nos valores de resistividade elétrica, sendo que as adições mais reativas atingiram resistividades elétricas superiores em relação ao traço de referência de cimento CPV ARI.
\end{abstract}

Palavras-chave: resistividade elétrica, durabilidade, adições pozolânicas.

Abstract: Electrical resistivity of concrete is a key parameter to assess reinforced concrete durability, since it regulates the speed of corrosion when the steel bar is in a state of active corrosion. In this context, the aim of this study is to investigate the influence of pozzolanic additions on the electrical resistivity of concrete measured by the Wenner probe method. For this research several specimens were made using Brazilian Cement CPV ARI with different pozzolanic additions: silica fume, rice-husk ash, metakaolin and fly ash. Cement was partially replaced by these pozzolanic additions by $10 \%$. The results showed that the pozzolanic additions affected the electrical resistivity, and the higher the reactivity of the pozzolanic addition, highest the electrical resistivity.

Keywords: electrical resistivity, durability, pozzolanic additions. 
REAL, L.; WOSNIACK, L. M.; DIONE, M., MEDEIROS, M.. INFLUÊNCIA DE MATERIAIS POZOLÂNICOS NA RESISTIVIDADE ELÉTRICA SUPERFICIAL DO CONCRETO. $4^{\circ}$ Simpósio Paranaense de Patologia das Construções (40 SPPC), artigo 4SPPC149, pp. 439 - 448, 2019. DOI: $10.4322 / 2526-7248.066$

\section{Introdução}

A resistividade elétrica é uma característica dos materiais em geral que representa o inverso da condutividade [1 - 3]. É um dos principais parâmetros utilizados no monitoramento do desenvolvimento da corrosão de armaduras em estruturas de concreto armado, podendo ser decisiva na velocidade de corrosão. Isso ocorre porque o fluxo de íons que se difundem pelo concreto através da solução aquosa presente nos poros determina o valor da resistividade elétrica. Esse parâmetro é sensível ao teor de umidade de equilíbrio do concreto, reduzindo com o aumento de água [4 - 6].

Segundo Helene [4], o concreto tem pelo menos duas regiões onde os valores de resistividade são distintos: uma mais superficial, e outra, mais interna. Considera-se que a avaliação da resistividade elétrica superficial (RES) é a mais importante para a corrosão, por se referir à camada do cobrimento, que interage com os ciclos de molhagem e secagem e com a agressividade do meio.

A RES é medida através da leitura de uma corrente elétrica gerada pela diferença de potencial (ddp) entre eletrodos posicionados sobre a superfície do concreto [7]. Ela pode ser quantificada através da (Eq. 1) [8].

$$
\rho=R \cdot \frac{A}{L}=\frac{V}{I} \cdot \frac{A}{L}
$$

Onde: $\rho$ : resistividade elétrica superficial (ohm.cm); R: resistência elétrica aparente (ohm); A: área da seção do material condutor $\left(\mathrm{cm}^{2}\right)$; L: distância entre eletrodos $(\mathrm{cm})$; $\mathrm{V}$ : diferença de potencial $(\mathrm{V})$; I: intensidade de corrente $(\mathrm{A})$.

No Brasil, não existe uma norma regulamentadora para o ensaio de resistividade elétrica superficial. Entretanto, os resultados podem ser avaliados usando os limites prescritos pelo boletim 192 do CEB [9], indicando a probabilidade de corrosão de uma estrutura de concreto armado. É importante ressaltar que os valores mostrados na

Tabela 1 foram determinados em ensaios laboratoriais com corpos de prova completamente saturados em água, condição de difícil reprodução em campo.

Tabela 1: Recomendações do CEB 192 (1989) para avaliar a probabilidade de corrosão nas armaduras de concreto [9]

\begin{tabular}{cc}
\hline Resistividade do concreto $\mathbf{( k \boldsymbol { \Omega } . \mathbf { c m } )}$ & Taxa provável de corrosão \\
\hline$>20$ & Negligenciável \\
10 a 20 & Baixa probabilidade \\
5 a 10 & Alta probabilidade \\
$<5$ & Muito alta probabilidade \\
\hline
\end{tabular}


REAL, L.; WOSNIACK, L. M.; DIONE, M., MEDEIROS, M.. INFLUÊNCIA DE MATERIAIS POZOLÂNICOS NA RESISTIVIDADE ELÉTRICA SUPERFICIAL DO CONCRETO. $4^{\circ}$ Simpósio Paranaense de Patologia das Construções (40 SPPC), artigo 4SPPC149, pp. 439 - 448, 2019. DOI: $10.4322 / 2526-7248.066$

Alguns fatores podem influenciar o resultado da RES avaliado através do método dos quatro pontos, tais como: relação água/cimento, origem e dimensão dos agregados, hidratação e tipo de cimento, presença de adições minerais, geometria da peça, temperatura e umidade do ambiente ou a presença de íons cloreto $[1,8,10]$. Dentro desse contexto, essa pesquisa teve como objetivo avaliar a influência de quatro pozolanas disponíveis no mercado (sílica ativa, cinza da casca do arroz, metacaulim e cinza volante) na resistividade elétrica superficial do concreto.

\section{Materiais e métodos}

\subsection{Traços e dosagem do concreto}

A fim de avaliar a influência de materiais pozolânicos na RES do concreto, foram elaboradas cinco dosagens diferentes (Tabela 2). O traço de referência (TCPV) foi composto com cimento CPV ARI, enquanto os demais tiveram substituição de $10 \%$ em massa de cimento pelas pozonalas sílica ativa (SA), sílica da casca de arroz (SCA), metacaulim (M) e cinza volante (CV).

Tabela 2: Traços unitários em massa

\begin{tabular}{l|ccccccccc}
\hline \multicolumn{1}{c}{ Traço } & CPV & SA & SCA & M & CV & Areia & Brita 1 & a/a* & Aditivo (\%) \\
\hline TCPV & 1,00 & - & - & - & - & 2,25 & 3,00 & 0,45 & 1,8 \\
TSA & 0,90 & 0,10 & - & - & - & 2,25 & 3,00 & 0,45 & 1,8 \\
TSCA & 0,90 & - & 0,10 & - & - & 2,25 & 3,00 & 0,45 & 1,3 \\
TM & 0,90 & - & - & 0,10 & - & 2,25 & 3,00 & 0,45 & 1,9 \\
TCV & 0,90 & - & - & - & 0,10 & 2,25 & 3,00 & 0,45 & 1,7 \\
\hline
\end{tabular}

* relação água/aglomerantes

Como a resistividade elétrica superficial é um parâmetro para controle da velocidade de corrosão do concreto armado, foi adotado o traço de referência considerando os parâmetros mais rígidos em relação ao meio ambiente, descrito pela NBR 12655 [11], referente à classe IV. Assim, os traços apresentam relação água/aglomerante igual a 0,45, consumo de cimento de $360 \mathrm{~kg} / \mathrm{m}^{3}$ e fck mínimo de $40 \mathrm{MPa}$. O cimento CPV ARI foi escolhido como referência devido ao baixo teor de adição de sua composição (até $5 \%$ de fíler calcário em relação à massa de clínquer).

Para manter a trabalhabilidade constante para todos os traços, possibilitando que todos fossem adensados com um mesmo padrão, a quantidade de aditivo utilizada foi variável, conforme pode ser observado na Tabela 2. O abatimento de todos os traços foi igual a $130 \pm 30 \mathrm{~mm}$.

\subsection{Caracterização das adições pozolânicas}

As pozolanas usadas nesta pesquisa foram caracterizadas pelo método Chapelle Modificado segundo a NBR 15895 [12] e pela técnica de difração de raios X investigando a existência de halo amorfo nos difratogramas. $O$ ensaio de Chapelle modificado é um método de determinação da atividade pozolânica por meio da determinação do teor de hidróxido de cálcio fixado, sendo expresso pela quantidade de hidróxido de cálcio consumido ou fixado por grama de material pozolânico (mg 
REAL, L.; WOSNIACK, L. M.; DIONE, M., MEDEIROS, M.. INFLUÊNCIA DE MATERIAIS POZOLÂNICOS NA RESISTIVIDADE ELÉTRICA SUPERFICIAL DO CONCRETO. $4^{\circ}$ Simpósio Paranaense de Patologia das Construções (40 SPPC), artigo 4SPPC149, pp. 439 - 448, 2019. DOI: $10.4322 / 2526-7248.066$

$\mathrm{Ca}(\mathrm{OH})_{2} / g$ pozolana) [12 - 15]. Podem ser observados na Figura 1 os resultados deste ensaio de reatividade pozolânica. Já na Figura 2 são apresentados os difratogramas das 4 adições avaliadas, com indicação dos halos amorfos em cada caso.

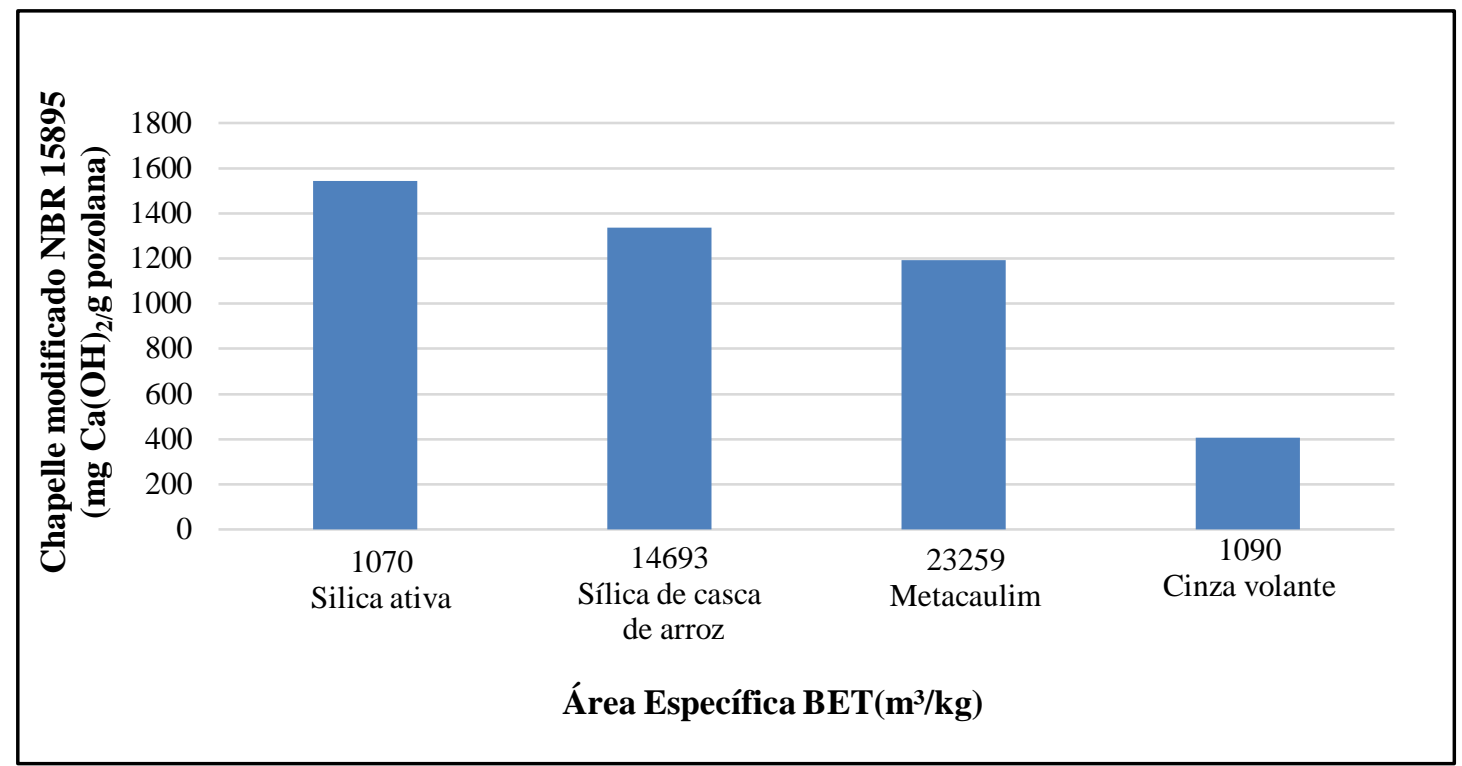

Figura 1: Comparação da Reatividade Pozolânica pelo Ensaio Chapelle modificado com a finura das amostras pelo método de BET

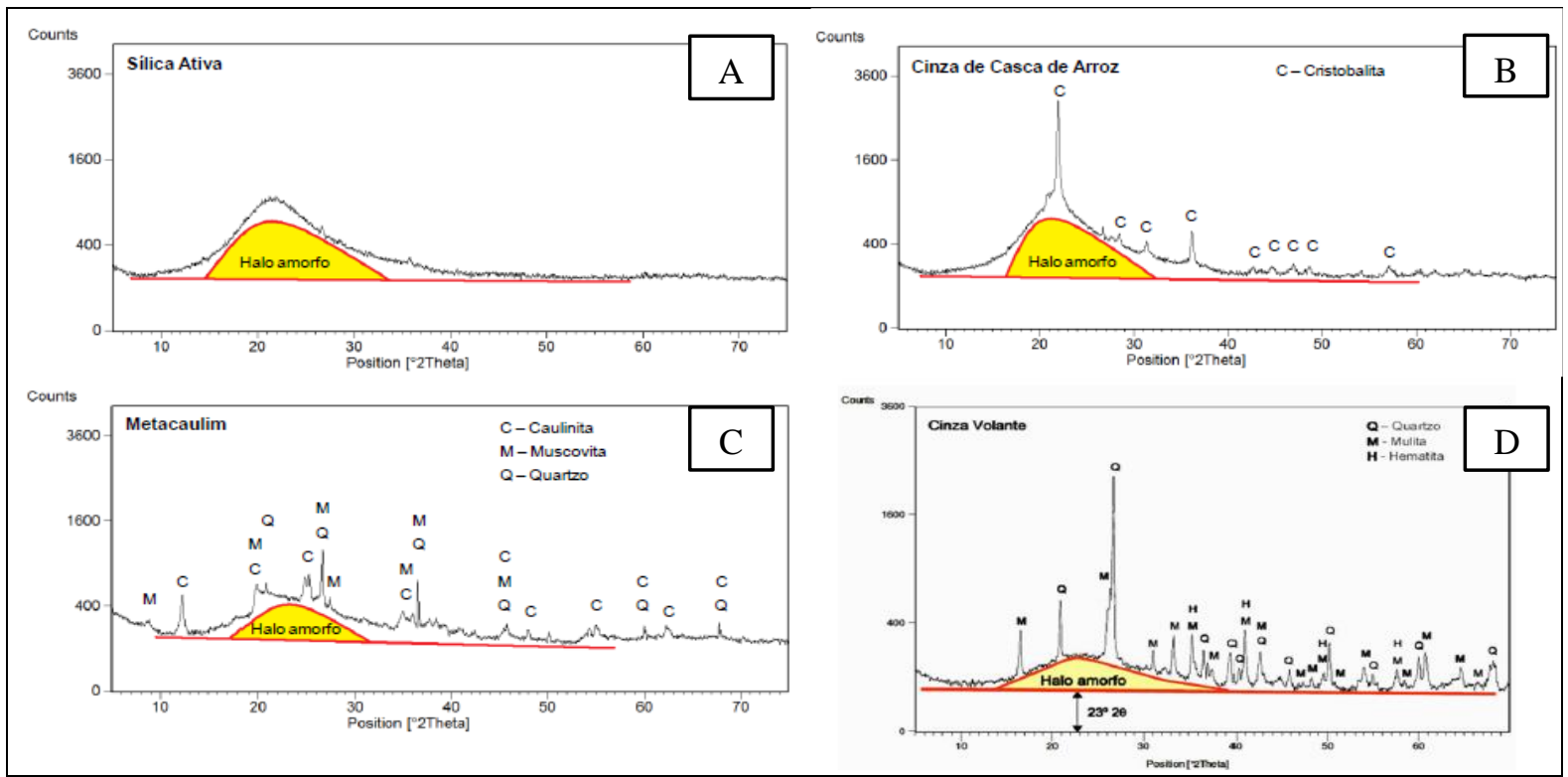

Figura 2: Difratogramas de materiais pozolânicos (halo amorfo) no estado anidro. A - sílica ativa, B - cinza de casca de arroz, C - metacaulim e D - cinza Volante [13]

As adições podem ser consideradas pozolânicas quando os valores de consumo de cal são superiores ao consumo de $330 \mathrm{mg} \mathrm{CaO} / \mathrm{g}$ de adição (equivalente a $436 \mathrm{mg}$ $\mathrm{Ca}(\mathrm{OH})_{2} / \mathrm{g}$ de adição) $[14,15]$, valor mínimo para classificação da adição mineral como material pozolânico [16]. Sendo assim, as adições de sílica ativa, cinza da casca de arroz e metacaulim podem ser consideradas pozolanas de alta reatividade. Neste 
REAL, L.; WOSNIACK, L. M.; DIONE, M., MEDEIROS, M.. INFLUÊNCIA DE MATERIAIS POZOLÂNICOS NA RESISTIVIDADE ELÉTRICA SUPERFICIAL DO CONCRETO. $4^{\circ}$ Simpósio Paranaense de Patologia das Construções (40 SPPC), artigo 4SPPC149, pp. 439 - 448, 2019. DOI: $10.4322 / 2526-7248.066$

experimento a cinza volante não mostrou atividade pozolânica no ensaio Chapelle modificado, apesar de ter apresentado halo amorfo no difratograma (Figura 2). Isso pode ter ocorrido por a cinza volante não ser tão fina quanto as outras adições.

\subsection{Resistividade elétrica pelo método de Wenner}

O método de Wenner ou dos quatro pontos é a técnica mais conhecida e empregada para a obtenção da RES [3, 17 - 19]. O ensaio consiste em colocar quatro eletrodos em contato direto com a superfície do concreto, úmida ou seca. Uma corrente é aplicada entre os dois eletrodos externos e consequentemente uma ddp é captada pelos eletrodos internos [1], como mostrado na Figura 3 A:

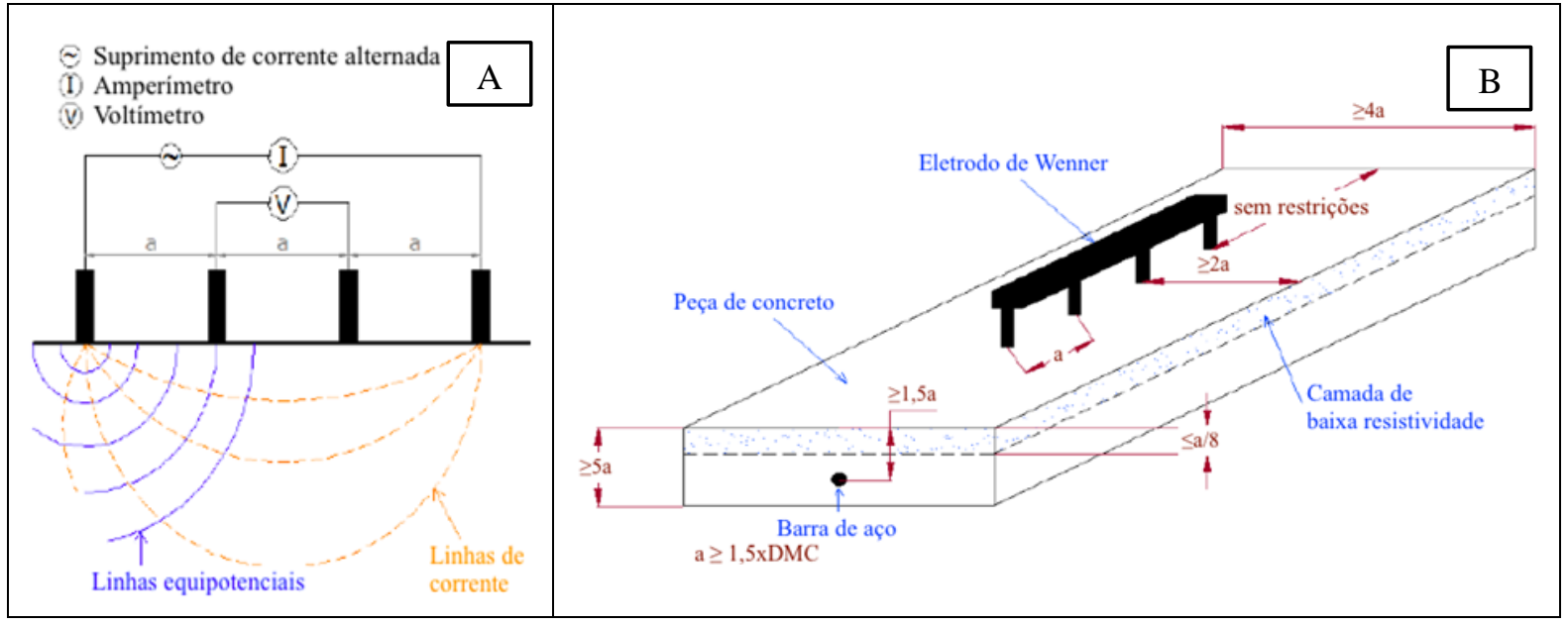

Figura 3: Ensaio com eletrodos de Wenner: A - esquematização [1]; B recomendações de parâmetros geométricos [20]

Na Figura 3 B são apresentados parâmetros geométricos adotados por Gowers \& Millard [20] para o método dos quatro pontos. Recomenda-se que espaçamento "a" seja menor do que $1 / 4$ da menor dimensão da peça de concreto entre eletrodos, para que as linhas de corrente se formem em semi-círculos, conforme apresentado na Figura 3 A. Assim, para avaliar a resistividade elétrica dos concretos mencionados, foram moldados corpos de prova cúbicos de aresta igual a $250 \mathrm{~mm}$, de maneira que a geometria da peça não influenciasse nas leituras de RES por simular um meio semi-infinito $[1,2,20]$.

Desta forma não foi necessário utilizar a correção do fator de forma [21] e o experimento foi realizado com espaçamento entre eletrodos equivalente à $50 \mathrm{~mm}$. $\mathrm{O}$ equipamento utilizado possui frequência de $40 \mathrm{~Hz}$ e corrente entre 10 e $200 \mu \mathrm{A}$.

As amostras foram desformadas com até $24 \mathrm{~h}$ de idade e permaneceram em câmara úmida até o momento das leituras, que foram realizadas em cada uma das faces dos cubos, gerando 6 leituras para cada um dos 5 corpos de prova irmãos para cada série de ensaio. Todas as medições de resistividade elétrica foram realizadas com 0 concreto saturado, seguindo a norma UNE 83988-2 [21]. 
REAL, L.; WOSNIACK, L. M.; DIONE, M., MEDEIROS, M.. INFLUÊNCIA DE MATERIAIS POZOLÂNICOS NA RESISTIVIDADE ELÉTRICA SUPERFICIAL DO CONCRETO. $4^{\circ}$ Simpósio Paranaense de Patologia das Construções (40 SPPC), artigo 4SPPC149, pp. $439-448$, 2019. DOI: $10.4322 / 2526-7248.066$

\section{Resultados e discussões}

Sendo 5 corpos de prova cúbicos para cada concreto, no total foram obtidas 30 leituras de resistividade elétrica por traço. O critério de Chauvenet [22] foi utilizado para identificar e posteriormente remover dados espúrios nos valores de RES de cada traço. Foi verificado que esses valores de RES se enquadravam em uma distribuição gaussiana normal utilizando o teste Shapiro-Wilk [23] com significância superior à 0.05 .

Apresenta-se na Figura 4 mostra os resultados médios das RES medidas aos 28 dias para cada traço.

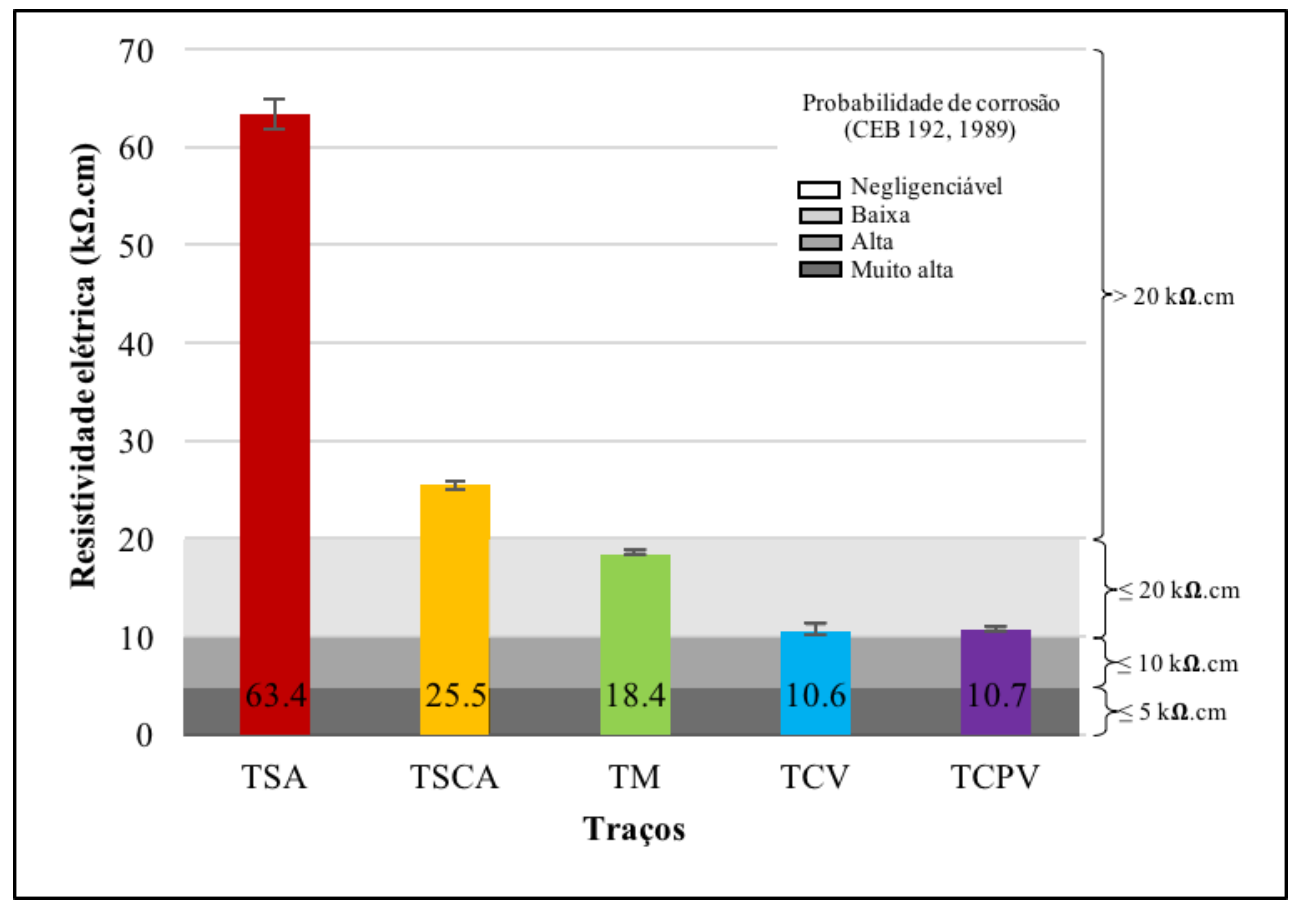

Figura 4: RES medida aos 28 dias de cura úmida pelo método dos 4 eletrodos

Analisando os resultados da Figura 4 e associando as medições com os limites sugeridos pelo CEB 192 [9], pode-se verificar que os traços de TSA e TSCA apresentaram as maiores RES e se enquadram na faixa negligenciável de risco de corrosão após 28 dias. Os demais traços se situam na faixa de baixa probabilidade de corrosão, com destaque para o traço TM que está muito próximo de atingir o 20 $\mathrm{k} \Omega . \mathrm{cm}$, que é o limite para alcançar a faixa de probabilidade negligenciável de desenvolver a corrosão.

A análise de variância (ANOVA) foi aplicada e demonstrou a existência pelo menos um contraste significativo nas comparações entre as RES dos traços, com fator de confiança de $95 \%$. O teste Tukey, por sua vez, foi aplicado para verificar a ocorrência de pares de traços que não fossem significativamente diferentes entre si. O resultado está mostrado na Figura 5 e foram destacados os casos nos quais os valores apresentaram semelhança. 


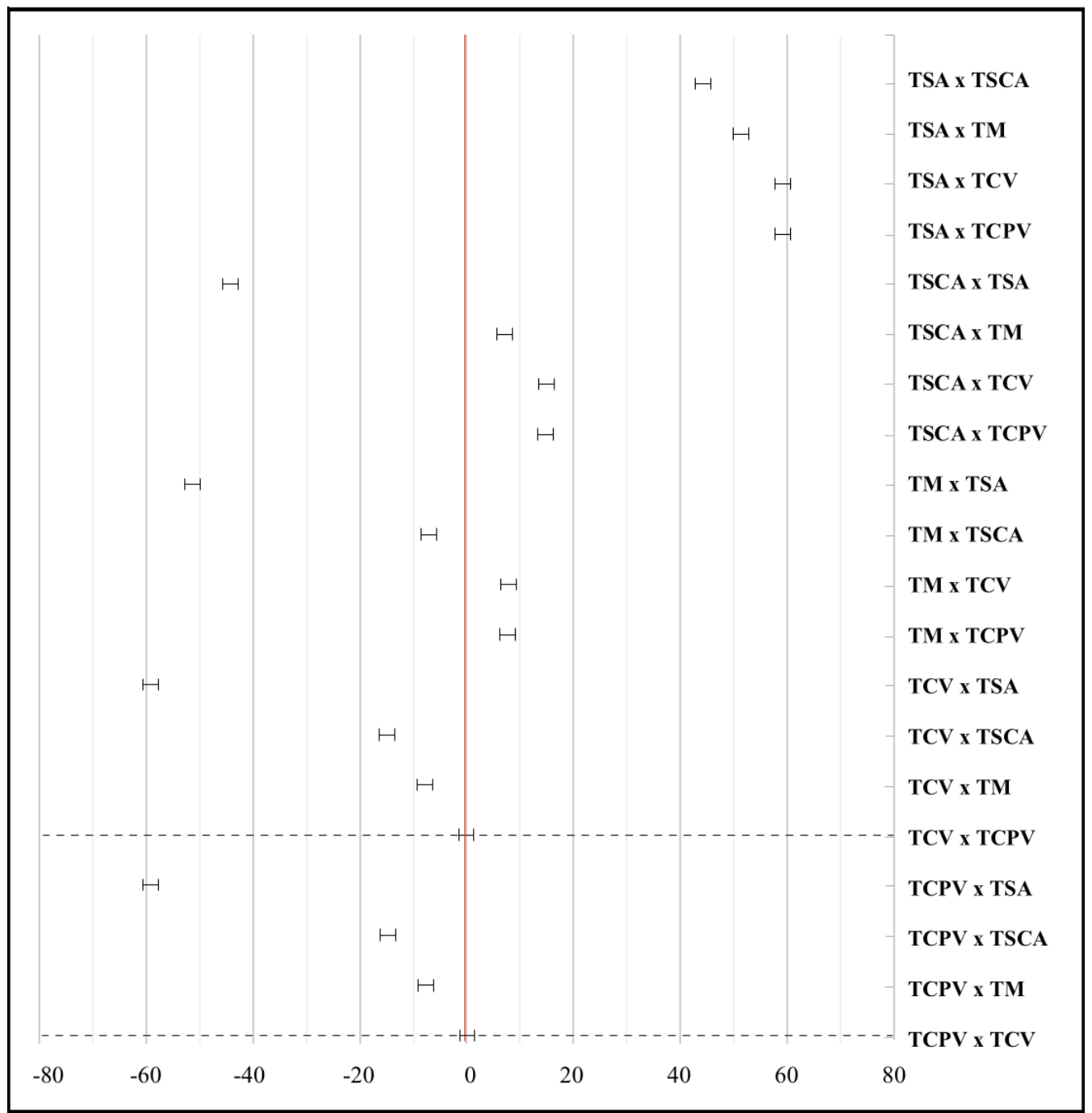

Figura 5: Teste Tukey sobre RES medida

Os valores das RES dos traços TCV e TCPV não foram significativamente diferentes entre si. Esse resultado sugere que a adição de $10 \%$ de cinza volante presente no TCV não interferiu na resistividade elétrica quando comparada ao cimento CPV-ARI, do traço TCPV.

Conforme mostrado na Tabela 2 e Figura 2, a cinza volante é uma adição de baixa reatividade e esse fator provavelmente justifica sua proximidade com a RES obtida com o TCPV aos 28 dias. As adições de metacaulim, cinza da casca de arroz e sílica ativa apresentaram RES $73 \%, 139 \%$ e $495 \%$ superiores ao traço TCPV. Esses resultados são coerentes com os dados obtidos no ensaio de determinação do teor de hidróxido de cálcio fixado, pois as adições mais reativas apresentaram as resistividades mais altas. Esse fator está associado ao refinamento e melhor distribuição do tamanho dos poros na microestrutura da pasta, o que certamente contribuiu para tornar a pasta mais densa e consequentemente dificultar a passagem da corrente elétrica. Além disso, a redução da portlandita consumida na reação pozolânica tende a reduzir a condutividade da água dos poros do concreto [24]. Estes argumentos indicam que a capacidade de reação pozolânica é um fator de influência na RES, como mostra a Figura 6. 

pp. 439 - 448, 2019. DOI: $10.4322 / 2526-7248.066$

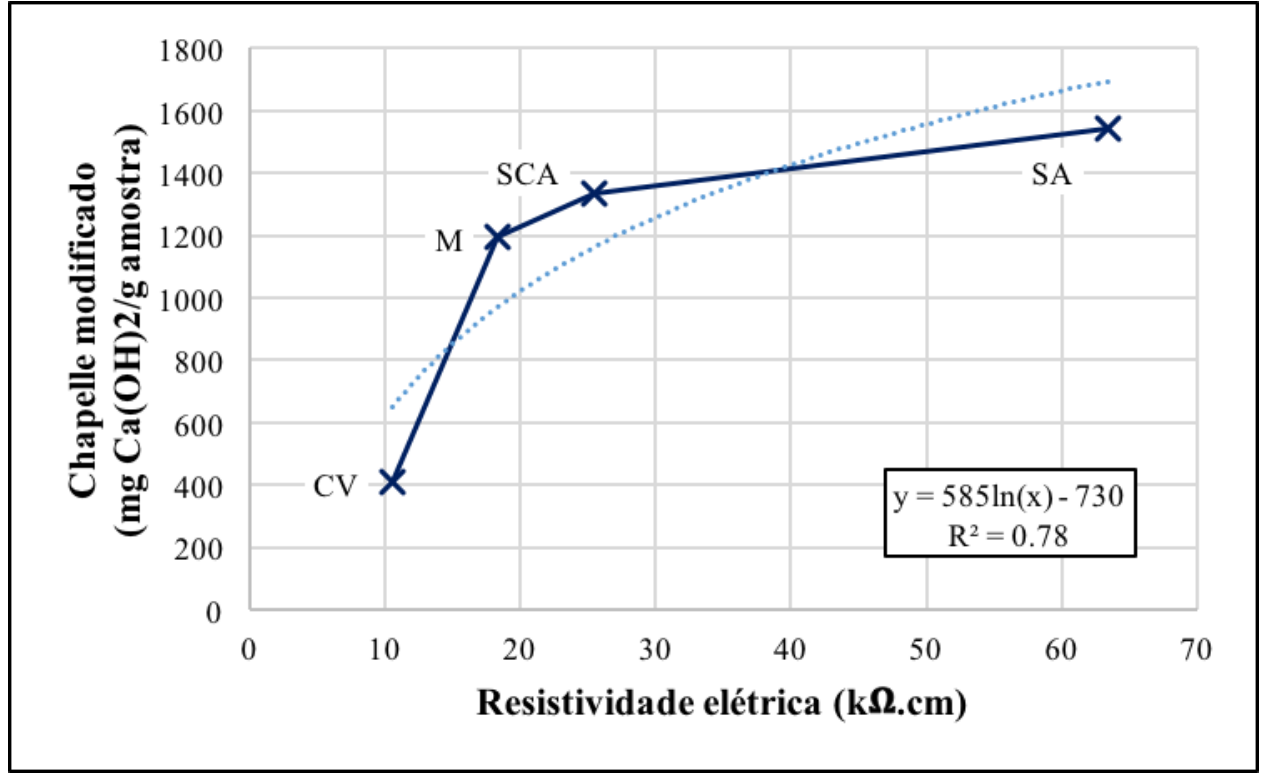

Figura 6: Correlação entre o ensaio de Chapelle modificado e a RES

O coeficiente de determinação de $\mathrm{R}^{2}=0,78$ (Fig. 6) mostra uma correlação positiva entre os valores de atividade pozolânica com os de resistividade elétrica, em conformidade com os demais resultados obtidos.

\section{Conclusão}

Este trabalho de pesquisa experimental tem como considerações finais:

- A utilização de diferentes adições pozolânicas impactou nos valores de resistividade elétrica medidos pela técnica dos 4 eletrodos;

- As adições mais reativas desenvolveram resistividades elétricas superiores aos do traço de referência (com apenas cimento CPV-ARI), enquanto o traço com $10 \%$ de adição de cinza volante não foi significativamente diferente do traço de referência;

- A capacidade de reação pozolânica possivelmente é um fator de influência na RES devido ao refinamento e melhor distribuição do tamanho dos poros na microestrutura da pasta, contribuindo para tornar a pasta mais densa e dificultar a passagem da corrente elétrica.

\section{Agradecimentos}

Os autores agradecem à infraestrutura e ao apoio em recursos humanos e financiamento à Coordenação de Aperfeiçoamento de Pessoal de Nível Superior (CAPES), ao Conselho Nacional de Desenvolvimento Científico e Tecnológico (CNPq) e à Universidade Federal do Paraná - PPGECC/UFPR. 
REAL, L.; WOSNIACK, L. M.; DIONE, M., MEDEIROS, M.. INFLUÊNCIA DE MATERIAIS POZOLÂNICOS NA RESISTIVIDADE ELÉTRICA SUPERFICIAL DO CONCRETO. $4^{\circ}$ Simpósio Paranaense de Patologia das Construções (40 SPPC), artigo 4SPPC149, pp. 439 - 448, 2019. DOI: $10.4322 / 2526-7248.066$

\section{Referências}

[1] Medeiros, M. H. F. (2001). Estudo de variáveis que influenciam nas medidas de resistividade de estruturas de concreto armado, Revista Engenharia Civil da Universidade do Minho, v.12, Guimarães, Portugal.

[2] Lencioni, J. W.; Lima, A. G (2010). Principais fatores intervenientes nas medidas de resistividade elétrica superficial do concreto - Estado-da-Arte, VI Congresso Internacional sobre Patologia e Reabilitação de Estruturas, Córdoba, Argentina.

[3] Salehi, M.; Ghods, P.; Isgor, O. B (2016). Numerical investigation of the role of embedded reinforcement mesh on electrical resistivity measurements of concrete using the Wenner probe technique, Materials and Structures, 49: 301-316, Suiça.

[4] Helene, P. (1993) Contribuição ao estudo da corrosão em armaduras de concreto armado, Tese (livre docência), Escola Politécnica, Universidade de São Paulo, Brasil.

[5] Sengul, O. (2014). Use of electrical resistivity as an indicator for durability, Construction and Building Materials, 73:434-441, Amsterdã, Holanda.

[6] Lima M.G.; Medeiros Jr, R. A. (2016) Electrical resistivity of unsaturated concrete using different types of cement. Construction and Building Materials, 107:11-16. Amsterdã, Holanda.

[7] Santos, L. (2006). Avaliação da resistividade elétrica do concreto como parâmetro para a avaliação da iniciação da corrosão induzida por cloretos em estruturas de concreto armado. Dissertação (mestrado), Universidade Federal de Brasília, Distrito Federal, Brasil.

[8] Lencioni, J. W. (2011). Estudos sobre resistividade elétrica superficial em concreto: análise e quantificação de parâmetros intervenientes nos ensaios. Tese (doutorado), Instituto Tecnológico de Aeronáutica, São José dos Campos, Brasil.

[9] CEB. 192. (1989). Bulletin D'Information Diagnosis and Assessment of concrete structures. Jan.

[10] Medeiros Junior, R. A.; Lima, M. G.; Medeiros, M. H. F.; Real, L. V. (2014). Investigação da resistência à compressão e da resistividade elétrica de concretos com diferentes tipos de cimento. Revista ALCONPAT, 4: 116-128, Brasil.

[11] NBR 12655 (2015). Concreto de cimento Portland - Preparo, controle e recebimento - Procedimento. Associação Brasileira de Normas Técnicas. ABNT. Rio de Janeiro, Brasil.

[12] NBR 15895 (2010). Materiais pozolânicos - Determinação do teor de hidróxido de cálcio fixado - Método Chapelle modificado. Associação Brasileira de Normas Técnicas. ABNT. Rio de Janeiro, Brasil.

[13] Gobbi, A. (2014). Atividade pozolânica de adições minerais pela NBR 5751/2012 e NBR 5752/2012: Uma análise crítica a partir de métodos complementares. Dissertação (Mestrado). Programa de Pós-Grad. em Eng. de Construção Civil Universidade Federal do Paraná, Brasil. 
REAL, L.; WOSNIACK, L. M.; DIONE, M., MEDEIROS, M.. INFLUÊNCIA DE MATERIAIS POZOLÂNICOS NA RESISTIVIDADE ELÉTRICA SUPERFICIAL DO CONCRETO. $4^{\circ}$ Simpósio Paranaense de Patologia das Construções (40 SPPC), artigo 4SPPC149, pp. 439 - 448, 2019. DOI: $10.4322 / 2526-7248.066$

[14] Hoppe Filho, J.; Gobbi, A.; Pereira, E.; Quarcioni, V. A.; Medeiros, M. H. $F(2017)$. Atividade pozolânica de adições minerais para cimento Portland (Parte I): Índice de atividade pozolânica (IAP) com cal, difração de raios-X (DRX), termogravimetria (TG/DTG) e Chapelle modificado. Materia-Rio de Janeiro, 22: 1-1. Rio de Janeiro, Brasil.

[15] Hoppe Filho, J.; Gobbi, A.; Pereira, E.; Tanaka, R. S.; Medeiros, M. H. F. (2017). Atividade pozolânica de adições minerais para cimento Portland (Parte II): Índice de atividade pozolânica com cimento Portland (IAP), difração de raios-X (DRX) e termogravimetria (TG/DtG). Materia-Rio de Janeiro, 22: 1-19. Rio de Janeiro, Brasil.

[16] Raverdy M., Brivot F., Paillere A. M., Dron, R. (1980). "Appreciation de l'activite pouzzolanique des constituants secondaires", In: 7th Int. Congr. Chem. Cem. Paris, France.

[17] Andrade, C.; D’andréa, R. (2011). La resistividad eléctrica como parámetro de control del hormigón y de su durabilidad. Revista ALCONPAT, n 2,1: 93-101, mai-ago, Brasil.

[18] Lübeck, A.; Gastaldinl, A. L. G.; Barin, D. S.; Siqueira, H. C. (2012). "Compressive strength and electrical properties of concrete with white Portland cement and blast-furnace slag", Cement and Concrete Composites, 34:392-399. Amsterdã, Holanda.

[19] Chu, H.-Y.; Chen, J.-K. (2016).The experimental study on the correlation of resistivity and damage for conductive concrete. Cement and Concrete Composites, 67: 12-19, Amsterdã, Holanda.

[20] Gowers, K. R.; Millard, S. G. (1999). Measurement of concrete resistivity for assessment of corrosion severity of steel using Wenner technique. ACI Materials Journal, 96-M66:536-541. Michigan, EUA.

[21] UNE 83988-2 (2012). Determinación de la Resistividade Eléctrica - Parte 2: Método de las cuatro puntas o de Wenner, Espanha.

[22] Oliveira, E. (2008). Comparação das diferentes técnicas para a exclusão de "outliers". ENQUALAB - Congresso da Qualidade em Metrologia Rede Metrológica do Estado de São Paulo - REMESP 09 a 12 de junho de 2008, São Paulo, Brasil.

[23] Ghasemi, A; Zahedias, S. (2012). Normality Tests for Statistical Analysis: A Guide for Non-Statisticians. International Journal of Endocrinology and Metabolism, 10(2):486-489, Teerã, Irã.

[24] Hoppe, T.F. (2005). Resistividade elétrica de concretos contendo diferentes teores de cinzas de casca de arroz. Dissertação (mestrado), Universidade Federal de Santa Maria, Santa Maria, Brasil. 